\title{
LOAD-DEFLECTION RESPONSE OF LAYERED FLEXIBLE PAVEMENT SECTIONS UNDER RIGID BEARING PLA'TES
}

\author{
Eiichi Yamamoto*, Robert L. KondneR** and Raymond J. KRIZEK ${ }^{* * *}$
}

\section{INTRODUCTION}

The analysis of load-deflection data from rigid plates bearing on flexible pavements is one technique often employed by the highway engineer to assist in the development of design criteria and estimation of the serviceability of pavements in use. At present, most methods of flexible pavement design employ a combination of theoretical and empirical procedures in conjunction with soil classifications; from the serviceability standpoint Walker et al. (1) ${ }^{\dagger}$ have observed that crack frequency is related statistically to the subbase modulus and deduced that subbase deformations, regardless of season, contributed to the occurrence of surface cracks. They also concluded that deflection measurements of the individual layers are useful in showing the relationship between pavement cracking and the properties of each layer. Layer deflections take on added significance when it is noted that some studies have indicated no correlation between serviceability parameters and surface deflections.

In accordance with these goals, this study presents an analysis of layer deflection data resulting from rigid plates bearing on flexible pavements. The data utilized has been given in tabular form by Benkelman and Williams (2) and is the result of a cooperative endeavor of the Highway Research Board, the Asphalt Institute, and the U.S. Bureau of Public Roads. The field investigation was conducted on a specially constructed track at Hybla Valley near Alexandria, Virginia. One of the prime objectives of the field study was to develop by means of static bearing load tests on fullsize pavement sections in the field fundamental data on the load-supporting value of nonrigid pavement surfacings of various thicknesses in combination with various base course thicknesses and degrees of subgrade support.

\section{TEST FACILITIES AT HYBLA VALLEY}

The site of the experimental test track is near Hybla Valley about four miles south

* Soils Engineer, Kobe, Japan.

** Consultant, Parkton, Maryland, Formerly with Department of Civil Engineering, The Technological Institute, Northwestaern University, Evanston, Illinois.

*** Department of Civil Engineering, The Technological Institute, Northwestaern University, Evanston, Illinois.

$\dagger$ Numbers in parentheses indicate references in the bibliography. 
of Alexandria, Virginia. Test sections consisted of various combinations of asphaltic concrete and base course thicknesses ranging from 0 to 12 inches and 0 to 24 inches, respectively. These pavement sections were constructed with great care on a minimum embankment of five feet of uniform A-7-6 soil (AASHO Classification-1949), and every precaution was exercised to insure uniformity of thickness, compaction and composition of the various component layers. The soil used in the embankment was secured from a previously prospected area, and a high degree of uniformity, both in composition and condition, was obtained. The first stages were completed in 1946, but some sections were not placed until 1949.

The pavement sections may be classified into two categories according to the function they are to serve. Auxiliary sections were constructed in advance of the test track to provide a test area for the large amount of preliminary work that was contemplated in developing test equipment, techniques and methods. These tests were primarily exploratory in nature rather than for the purpose of obtaining quantitative data. The main sections were built on the north and south tangents of the oval test track and provide the test area for obtaining the quantitative data analyzed herein.

\section{DESCRIPTION OF TEST PROCEDURES}

There are innumerable possible procedures for conducting static load tests. For any given pavement section the various controllable factors that may affect the results of tests of this type include the magnitude of the load and the manner in which it is applied, the number of applications and releases of a given load, the duration of each load application and release, and the size of the bearing plate. A further discussion of such variables has been given by Kondner and Krizek (3). The data presented by Benkelman and Williams were obtained by the use of four different load-test procedures; namely, the incremental, the incremental-repetitional, the accelerated, and the repetitional. The vast majority of the tests were made with the accelerated and repetitional procedures. Further details regarding these test procedures can be obtained from HRB SR 46 (2).

\section{DIMENSIONAL ANALYSIS}

Because of the complex properties of the various pavement materials and the complicated interaction of these various layers with the loads being supported, the use of nondimensional techniques in both model and prototype research investigations of pavement problems seems to offer definite advantages. This study not only provides an analysis of a portion of the Hybla Valley test data, but it illustrates an application of nondimensional techniques in the field of pavement design. One previous example has been reported by Kondner and Krizek (4).

The methods of dimensional analysis as used to determine relationships between physical quantities may be briefly summarized as follows, Kondner (5): "If there are $\mathrm{m}$ physical quantities containing $\mathrm{n}$ fundamental units which can be related by an equation, then there are $(m-n)$, and only $(m-n)$, independent nondimensional parameters, called $\pi$ terms, which are arguments of an indeterminate homogeneous 
VOL. VII, NO. 2, 1967

Table 1. Physical Quantities Considered for the Rigid Bearing Plate Tests of Flexible Pavements

\begin{tabular}{l|c|c}
\hline \multicolumn{1}{c|}{ Physical Quantities } & Symbol & Fundamental Units \\
\hline Deflection & $x$ & $\mathrm{~L}$ \\
Applied pressure & $p$ & $\mathrm{FL}^{-2}$ \\
Thickness of asphaltic concrete & $a$ & $\mathrm{~L}$ \\
Thickness of base course & $b$ & $\mathrm{~L}$ \\
Bearing plate diameter & $d$ & $\mathrm{~L}$ \\
Time & $t$ & $\mathrm{~T}$ \\
Soil unconfined compressive strength & $q$ & $\mathrm{FL}^{-2}$ \\
Characteristic soil viscosity & $\eta$ & $\mathrm{FL}^{-2} \mathrm{~T}$ \\
Asphaltic concrete strength parameter & $k_{1}$ & $\mathrm{FL}^{-2}$ \\
Characteristic asphaltic concrete viscosity & $C_{1}$ & $\mathrm{FL}^{-2} \mathrm{~T}^{-2}$ \\
Base course strength parameter & $k_{2}$ & $\mathrm{FL}^{-2}$ \\
Characteristic base course viscosity & $C_{2}$ & $\mathrm{FL}^{-2} \mathrm{~T}^{0}$ \\
Number of load applications & $N$ & $\mathrm{FL}^{0} \mathrm{~T}^{0}$ \\
\hline
\end{tabular}

function $F$, that is,

$$
F\left(\pi_{1}, \pi_{2}, \pi_{3}, \ldots \ldots, \pi_{\mathrm{m}-\mathrm{n}}\right)=0 . "
$$

The physical quantities given in Table 1 have been selected for use in the dimensional analysis of the problem of the rigid plate bearing test on the surface of a flexible pavement section. A force-length-time system of fundamental units has been employed.

It is assumed that the material constants needed to describe the deformation characteristics of the subgrade and various pavement layers are implicit in characteristic strength and viscosity parameters for the materials. The characteristic strength parameters may be unconfined or triaxial compressive strengths, compression or shear moduli, or some other form of material strength property, such as density. The characteristic viscosity parameter for a material controls the rate at which the deformation takes place and may include non-Newtonian effects. This is an important factor about which very little applicable quantitative information is known in the case of many engineering materials. For circular bearing plates, the effect of geometry is expressed by the diameter.

Because there are thirteen physical quantities and three fundamental units, there must be ten independent nondimensional $\pi$ terms. By a methodical process described by Kondner (5), the following terms can be obtained:

$$
\left.\begin{array}{ll}
\pi_{1}=\frac{p}{q} & \pi_{6}=\frac{k_{2}}{q} \\
\pi_{2}=\frac{x}{d} & \pi_{7}=\frac{q t}{\eta} \\
\pi_{8}=\frac{a}{d} & \pi_{8}=\frac{k_{1} t}{C_{1}}
\end{array}\right\}
$$




$$
\begin{array}{ll}
\pi_{4}=\frac{b}{d} & \pi_{9}=\frac{k_{2} t}{C_{2}} \\
\pi_{5}=\frac{k_{1}}{q} & \pi_{10}=N
\end{array}
$$

The above $\pi$ terms can be substituted in Equation 1 to obtain the function F.

A general interpretation of these $\pi$ terms can be given as follows. The terms $\pi_{1}$, $\pi_{5}$, and $\pi_{6}$ express the strength ratios of the subgrade, asphaltic concrete, and base course, respectively. The ratios of the time of loading to the relaxation time for the subgrade, asphaltic concrete, and base course are given by $\pi_{7}, \pi_{8}$, and $\pi_{9}$, respectively. The terms given by $\pi_{3}$ and $\pi_{4}$ are characteristic length ratios while $\pi_{2}$ is the settlement parameter. The number of load applications is dimensionless and is given by $\pi_{10}$. Considering $p / q$ as the dependent variable for the study, the functional relationship given by Equation 1 can be written

$$
\frac{p}{q}=F\left[\frac{x}{d}, \frac{a}{d}, \frac{b}{d}, \frac{k_{1}}{q}, \frac{k_{2} q t}{q \eta}, \frac{k_{1} t}{C_{1}}, \frac{k_{2} t}{C_{2}}, N\right],
$$

where $\mathrm{F}$ denotes "some function of " but not necessarily the same function in every instance.

For the reported Hybla Valley test data, $q, \eta, k_{1}, C_{1}, k_{2}$, and $c_{2}$ will be assumed constant ; hence, if $t$ can be regarded as sufficiently large that its effect is minimized, the terms, $k_{1} / q, k_{2} / q, q t / \eta, k_{1} t / C_{1}$, and $k_{2} t / C_{2}$ may be considered nearly constant and eliminated from Equation 3. This does not mean that the load-deflection response is independent of the type and quality of pavement materials, but only that the pavement materials were constant for the data analyzed. It is to be expected that the relationships would be different for different pavement materials and perhaps even for different types of loading. Thus, restricting the analysis to the Hybla Valley data and the assumptions mentioned, Equation 3 may be written

$$
\frac{p}{q}=F\left[\frac{x}{d}, \frac{a}{d}, \frac{b}{d}, N\right]
$$

For the portions of the analysis which deal with only one load application, Equation 4 may be further reduced to the form

$$
\frac{p}{q}=F\left[\frac{x}{d}, \frac{a}{d}, \frac{b}{d}\right] .
$$

According to Yoder (6), the classical linear elastic analysis of flexible pavement deflections yields equations of the form

$$
\frac{x}{d}=\frac{p}{E} K
$$

where $\mathrm{E}$ is the modulus of elasticity of the subgrade and $\mathrm{K}$ is a dimensionless factor which is a function of the thicknesses and moduli of the pavement layers. Perhaps. 
the oldest method of analysis is based on the Boussinesq stress problem which deals with an ideally elastic, homogeneous, isotropic, weightless half-space. This analysis was later modified by Burmister $(7,8)$ to account for layered systems. Fox (9) extended the Burmister solution, and Jones (10) presented tabulated stresses for the three layer problem. The combination of Equation 6 with a stiffness relation was first accomplished by Palmer and Barber (11) and later expanded by Baker and Papazian (12). Researchers are constantly attempting to check theoretical calculations with actual values existing in flexible pavement systems, but as a rule such quantitative checks are not obtained. One reason may be the inherent linearity between load and deflection implied by Equation 6. The more general relation expressed by Equation 5 does not include this restriction of linearity, and such an assumption will not be proposed in this analysis. The particular analytic form of Equation 5 for the Hybla Valley test results will be determined by an empirical investigation of the actual data.

\section{EXPERIMENTAL RESULTS}

\section{Previous Studies of Hybla Valley Data}

At least two previous attempts have been made to analyze various portions of the Hybla Valley data reported in HRB SR 46. The first of these was reported by Ingimarsson (13) wherein he analyzed 89 rigid plate bearing tests on 26 different flexible pavement sections; these data appear in Tables 4 and 7 of HRB SR 46 . Using the linear perimeter shear equation developed by Housel (14), Ingimarsson carries his analysis to the point of determining the stress reactions developed by the flexible surfaces and supporting subgrade and presents his results graphically. Ingimarsson considered the initial repetitive loading cycle of the accelerated test procedure as a seating process and concentrated his analysis on the higher ranges of load aimed at determining the ultimate supporting capacity of the flexible pavements. Although several strong trends are consistent throughout the entire test series, Ingimarsson found numerous peculiarities associated with the complete interpretation of these stress reactions. In a discussion of Ingimarsson's work, Housel (15) raises the following points which are yet to be answered. The limit of the supporting capacity for the Hybla Valley tests is not reached until the deflection is much higher than the range of thousandths of an inch normally considered in current practice. Determining the source of these abnormally high deflections and correspondingly high values of perimeter shear is peculiarly perplexing. Housel further suggests that much of the difficulty with the analysis of rigid plate bearing tests on flexible pavements may be their relative rigidity and the secondary dimensional effects which they induce; these effects may mask the basic supporting capacity which the tests attempt to measure. After spending some time in an attempt to interpret the stress reactions developed in the Hybla Valley tests in the quantitative terms of the linear equation for bearing capacity used by Ingimarsson, Housel has not come to any final conclusion.

A second attempt to analyze portions of the Hybla Valley data was reported by Kondner and Krizek (4). Their analysis considered only data from Table 4 of HRB SR 
46 and was based on methods of dimensional analysis. In contrast to the range of deflection considered by Ingimarsson, these authors examine the low deflection region of the data. They approximate the load-deflection relationship by a straight line through the origin and explicitly express the surface deflection as a function of the applied load, bearing plate diameter, various pavement thicknesses and strength characteristics of the subgrade.

\section{General Approach}

The analysis pursued herein will be based on the methods of dimensional analysis and will be a continuation of the approach previously reported by Kondner and Krizek (4). However, three variations will be included in an effort to make the analysis were general. First, the data analyzed will be more extensive, including rigid plates on the subgrade alone (Table 3) (see Kondner and Krizek (16)), subgrade plus asphaltic concrete surface course (Table 7), subgrade plus base course and surface course (Tables 4 and 8), temperature variations (Table 6) and repetitional loading (Table 8). Second, consideration will be given to the deflections of the various component layers of the pavement structure. The significance of such layer deflections has been reported by Walker et al. (1). Third, the load-deflection relationship will be approximated by a hyperbola in rectangular cartesian coordinates. It is felt that this equation (rather than the simple proportionality afforded by a linear one) will make possible a better fit of available data and facilitate a better correlation among the various pavement component thicknesses.

The properties of the hyperbola lend themselves quite appropriately to describing the response observed in a typical load-deflection test. Applications of hyperbolic fits have been reported by Kondner (17) for the analysis of stress-strain response and Kondner and Krizek ( 3 ) for the correlation of load bearing tests ; the use of the equation and the method of determining the empirical constants has been explained in detail and will not be repeated herein. Using the hyperbolic formulation, Equation 4 may be written as

$$
\frac{p}{q}=\frac{\frac{x}{d}}{A+B \frac{x}{d}}
$$

where $A$ and $B$ are functions of $a / d, b / d$ and $N$; for any given test $A$ and $B$ are the intercept and slope, respectively, of the straight line describing the data on a transformed hyperbolic plot of $x q / d p$ versus $x / d$. If desired, the dependent and independent variables in Equation 7 may be interchanged to yield

$$
\frac{x}{d}=\frac{A \frac{p}{q}}{1-B \frac{p}{q}}
$$


The variable $x$ may represent the gross deflection $x_{G}$, pavement deflection $x_{p}$, base course deflection $x_{B}$, or subgrade deflection $x_{S}$; the specific deflection under study at any point will be identified appropriately. The graph of these transformed hyperbolic variables will be approximated by a " best fit" straight line as determined by observation, and the resulting dimensionless coefficients $A$ and $B$ will then be examined to deduce their dependence on thicknesses of component pavement layers and number of repetitions.

The original data corresponding to each individual test will be examined in terms of the dimensionless parameters $p / q$ and $x / d$ or some modification thereof. The unconfined compressive strength $q$ of the soil immediately under the test plate was apparently not measured (at least, these data are not given in HRB SR 46), nor was any measure of water content taken from which q might be estimated. In view of this and since most of the tests were conducted in a relatively short period of time, it might be reasonable to expect that the soil strength varied little during the test period. For purposes of this analysis $q$ will be considered constant; furthermore, since an actual value is not readily available, results will be expressed in terms of a normalized unconfined compressive strength $q_{N}$ equal to unity. If the required soil strength data becomes available, modification of the developed equations may be made to eliminate $q_{N}$ and express the equations in terms of $q$.

\section{Duplicability of Test Results}

In order to possess a high degree of reliability, any test program must exhibit good duplicability for any test within its scope. Such a condition is not satisfied in many cases for the Hybla Valley test results. For data which do not exhibit good duplicability, as is often the case in field situations, a coherent analysis is not possible unless some estimate is made regarding the test most nearly representing the "true" situation. Most of the time in the analysis herein, an average value was used; however, occasionally one or two tests were disregarded completely and the average of the remaining tests was used. Such decisions are consistent with the exercise of engineering judgment.

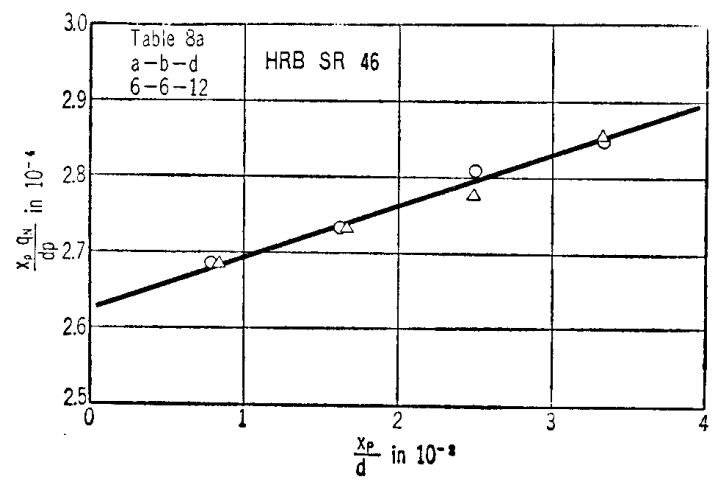

Fig. 1. Transformed Plot of Applied Pressure Parameter versus Pavement Deflection Parameter: Good Duplicability 
Figure 1 shows an example of test data plotted in transformed hyperbolic parameters. This figure illustrates the results of two tests which exhibit good duplicability and a good hyperbolic fit; hence, no difficulty is encountered in the determination of the dimensionless constants $A$ and $B$. However, such is not the case for all test data. On some occasions the results of two similar tests exhibit essentially the same slope B but have quite a different intercept $A$. The choice becomes somewhat subjective. In other instances, the results of two supposedly similar tests demonstrate drastically divergent behavior, such as a negative slope $\mathrm{B}$. The negative slope indicates that the resistance to deformation becomes greater as the load increases. In still other cases, the data are such that the average results provide a quite acceptable straight line, but the individual tests themselves are open to substantial doubt. Finally, there are cases where three or four supposedly identical tests were conducted, and all but one were reasonably compatible. Such is an example where one test was disregarded and the average of the remaining tests was used to determine an acceptable straight line to represent the data.

It is evident that such divergent results can never be reconciled in any coherent exact analysis and provide one reasonable explanation for the peculiarities observed by Ingimarsson (13) and Housel (15). Furthermore, in the absence of any explanation for such variance in response among supposedly identical tests, the results of other tests in the program must be viewed with suspicion. Thus, in this light it appears that the establishment of trends among the variables must be an end in itself and any attempt at an exact analysis encompassing all test data must be precluded.

\section{Test Data on Subgrade}

This section considers the analysis of data resulting from rigid bearing plates resting directly on the subgrade. Some aspects of these data were previously considered by Kondner and Krizek (16). The data are tabulated in Table 3 of HRB SR 46 and tests were conducted in the following manner. Bearing plates ranging from 12 to 84 inches in diameter were loaded to a specified level and the gross deflection was measured;

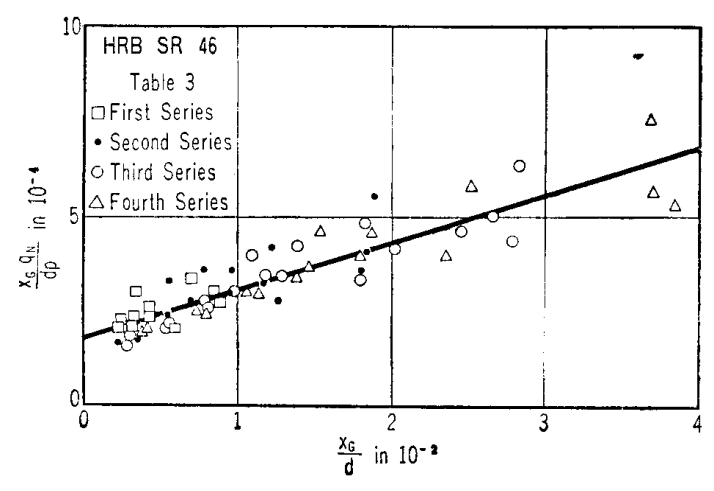

Fig. 2. Transformed Plot of Applied Pressure Parameter versus Gross Subgrade Deflection Parameter: HRB SR 46 Table 3

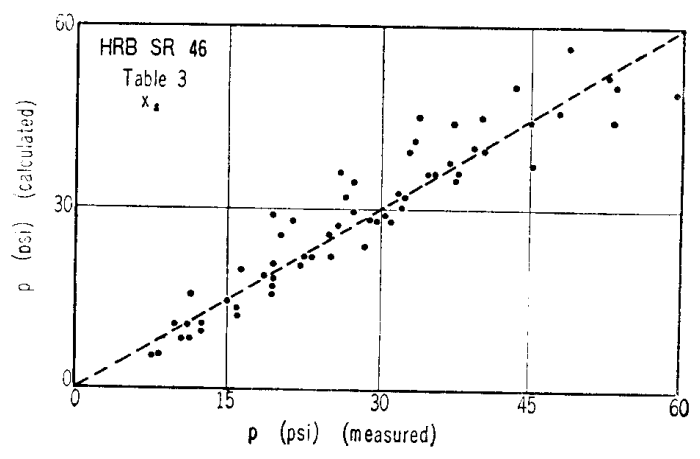

Fig. 3. Correlation Plot of Applied Pressures: HRB SR 46 Table 3 Subgrade Deflection 
following this, the load was released and the elastic deflection was measured. This process was repeated four more times at the same load level. Then the load was increased to three successively higher levels, there being five cycles with corresponding measurements at each particular level. The data used herein result from the gross deflections for the first cycle at each load level for the 17 tests conducted on the subgrade of the south tangent. It is recognized that measurements made on the second, third and fourth series may be influenced by the history imposed by previous loadings, but in the absence of any information to quantitatively evaluate this effect all data from each series are considered together. These data are plotted in terms of the transformed hyperbolic parameters $x_{G} q_{N} / d p$ and $x_{G} / d$ in Figure 2. Approximating these data by the straight line shown, the dimensionless coefficients $\mathrm{A}$ and $\mathrm{B}$ are found to be 0.00018 and 0.0125 , respectively. Hence, following the general form of Equation 7 , a descriptive equation for these data may be written as

$$
\frac{p}{q}=\frac{x_{G} / d}{0.00018+0.0125 x_{G} / d}
$$

A correlation plot of pressures calculated by Equation 9 and measured pressures given in Table 3 of HRB SR 46 is presented in Figure 3.

\section{Test Data on Subgrade Plus Surface Course}

These data were obtained from Table 7 of HRB SR 46. For these tests the subgrade was overlain by an asphaltic surface course with a thickness of 3,6 or 12 inches. Rigid bearing plates with diameters of $12,18,24$, and 30 inches were employed. The test data were obtained by the accelerated test procedure which is described in HRB SR 46. In brief, this test procedure consists of measuring the load required to cause a surface deflection of 0.1 inch, and then releasing the load; the same is done for surface deflections of $0.2,0.3$, and 0.4 inches. After release of the load causing a 0.4 inch surface deflection, a continuous load of increasing magnitude is applied until (a) the material is unable to support a further increase, or (b) the gross deflection ex-

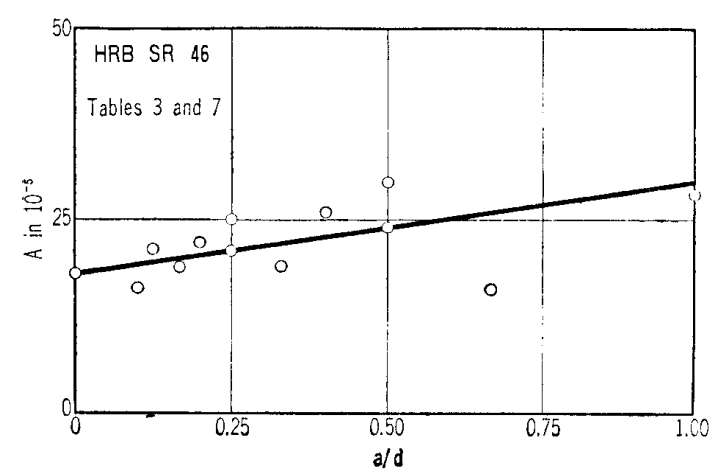

Fig. 4a. Intercept Parameter versus Surface Course Thickness Parameter: HRB SR 46 Table $3 \& 7$

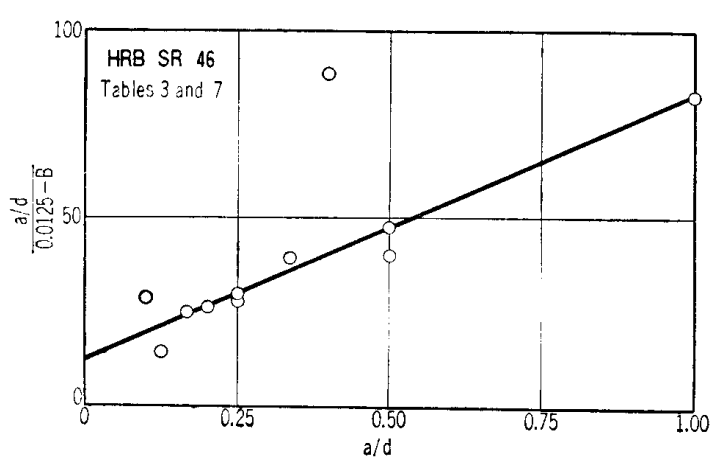

Fig. 4b. Transformed Plot of Slope Parameter versus Surface Course Thickness Parameter: HRB SR 46 Tables $3 \& 7$ 
ceeds two inches, or (c) the total reaction is utilized. The rate of application of the load is controlled so as to produce a rate of vertical movement of the surface under test of 0.5 inches per minute. The magnitudes of the loads to produce $0.1,0.2,0.3$, and 0.4 inches surface deflection are estimated and the respective deflections are intended to be guides only; however, in the absence of the actual deflections (which are not recorded in Table 7) the only recourse is to use these guides as the " true " deflections. The magnitude of the error so induced can not be readily determined.

Utilizing the data for the initial portion of each test (that is, up to deflections of 0.4 inches), the results are plotted in terms of transformed hyperbolic parameters and values for $\mathrm{A}$ and $\mathrm{B}$ are determined. In general, these values may be regarded as functions of the dimensionless term $a / d$. A plot of A versus $a / d$ is shown in Figure 4a. These data can be approximated by a straight line whose equation is

$$
A=0.00018+0.00012 \frac{a}{d} \text {. }
$$

If values for $B$ are plotted in the form of $(a / d) /(0.0125-B)$ versus a $/ \mathrm{d}$ and approximated by a straight line, as shown in Figure $4 b$, solution of the resulting equation for $B$ yields

$$
B=0.0125-\frac{\frac{a}{d}}{12+70 \frac{a}{d}} .
$$

Note that when $a / d$ reduces to zero (that is, the plate rests directly on the subgrade), Equations 10 and 11 reduce to the values for $A$ and $B$ as determined in the previous section for the analysis of bearing plates on subgrade. Values for $A$ increase slightly with increasing $a / d$ while values for $B$ decrease considerably with increasing $a / d$. This means that for a given diameter plate the presence of a thicker asphaltic concrete surface course causes the initial slope of the load-deflection graph to be somewhat flatter (less stiff) while the ultimate supporting capacity is significantly increased. Substituting Equations 10 and 11 into Equation 7 gives the general equation re-

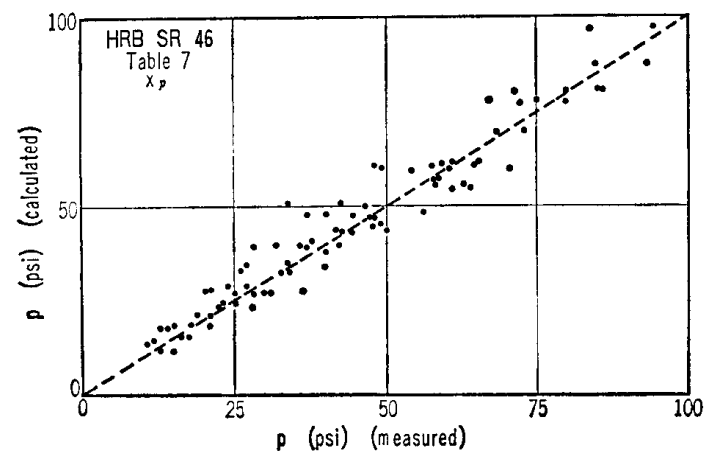

Fig. 5. Correlation Plot of Applied Pressures: HRB SR 46 Table 7 Pavement Deflection 
presenting the trend of response for rigid bearing plates on subgrade overlain with an asphaltic surface. The correlation plot of Figure 5 shows the reliability of the resulting equation to represent the experimental data.

\section{Test Data on Subgrade Plus Surface and Base Courses}

\section{a. Data Analyzed and Discussion of Techniques}

The data analyzed in this section will be taken from Table 4 of HRS SR 46. It will consist of the surface or pavement, base course, and subgrade deflection data from the cyclic portion of the accelerated test procedure (described in the previous section) for the complete pavement sections ; that is, the pavement sections for which no component layer was removed and the bearing plate was placed on the asphaltic concrete surface layer. However, for such sections deflections were measured at all three layers by a procedure described in HRB SR 46. The significance of layer deflection measurement has been discussed by Walker et al. (1)

In general, the method of approach to this analysis is similar to that already described. Individual test data were plotted in transformed hyperbolic form and results approximated by a straight line from which the dimensionless coefficients $A$ and $B$ were determined. These coefficients were then investigated as functions of the characteristic layer thickness parameters $a / d$ and $b / d$, or some reasonable combination thereof. Various unsuccessful attempts were made to establish formulations for $\mathrm{A}$ and $\mathrm{B}$ while maintaining the independence of $a / d$ and $b / d$; finally, the most successful technique was the use of an assumed relationship between $a / d$ and $b / d$, as given by

$$
\frac{D}{d}=0.44 \frac{a}{d}+0.14 \frac{b}{d}
$$

Equation 12 is based on test data from the AASHO Road Test and is described in HRB SR 61E (18). Since, in general, the pavement materials and subgrade for the Hybla Valley project were different from those at the AASHO Road Test, there is no reason to conclude a priori that the thickness index relation determined on the AASHO Project will be applicable to the Hybla Valley data. However, it was found to be quite effective in reducing the Hybla Valley data to a more compact form and hence seems to be very applicable. Of course, the ultimate goal of such research is to establish relationships as these which may be employed interchangeably on different pavement projects.

The particular forms of the variables plotted in the succeeding graphs represent extensive effort in making these choices. Preliminary choices which did not yield satisfactory relationships are not shown. The criterion for a satisfactory relationship is the absence of any orderly sequence among the variables under consideration. Although the different combinations of these variables are too numerous to employ any satisfactory or comprehensive legend in the following graphs, a detailed examination of any one graph will reveal a high degree of random scatter. The width of the bands of data appear to be the result of inconsistencies among the original tests ; any 
attempt to narrow the band resulted in the introduction of some order among the data points. Hence, the result achieved is essentially the establishment of appropriate equations representing the trends demonstrated by these data within the respective ranges of the variables considered.

\section{b. Pavement Deflections}

Each test utilized in Table 4 of HRB SR 46 was plotted in terms of the transformed hyperbolic variables $x_{p} q / d p$ and $x_{p} / d$, and the dimensionless coefficients $A$ and $B$ were determined. Plotting these coefficients (adjusted where convenient) in Figures 6a and $6 \mathrm{~b}$ and approximating the data by the curves shown yields the following expression :

$$
\frac{a b}{d^{2}} A=4(10)^{+3.33 D / d-6}
$$

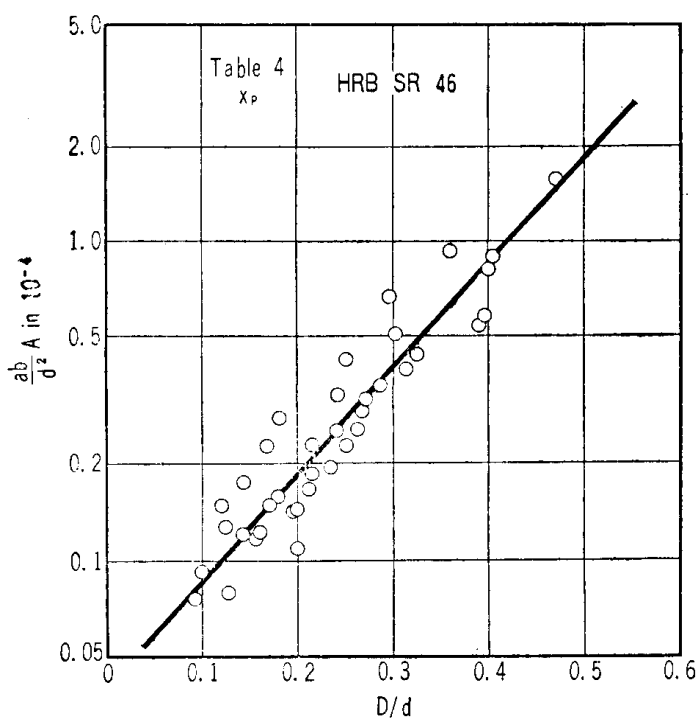

Fig. 6a. Intercept Parameter versus Thickness Index Parameter: HRB SR 46 Table 4 Pavement Deflection

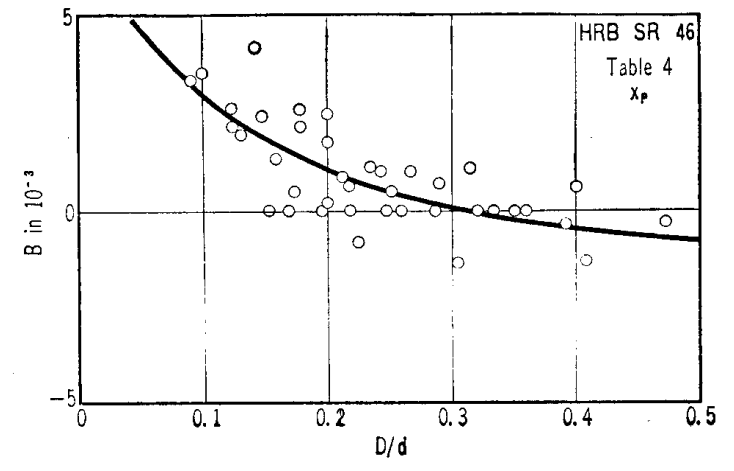

Fig. 6b. Slope Parameter versus Thickness Index Parameter: HRB SR 46 Table 4 Pavement Deflection

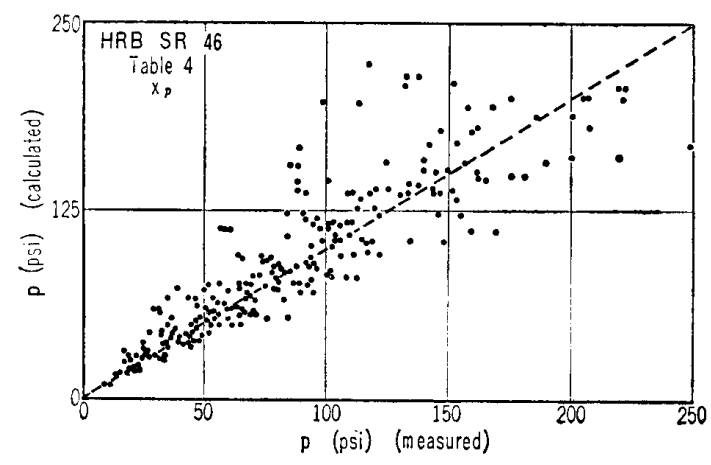

Fig. 7. Correlation Plot of Applied Pressures: HRB SR 46 Table 4 Pavement Deflection 
and

$$
B=8(10)^{-8 D / d-8}-0.001
$$

Solving Equation 13 for A, and substitution of this relationship plus the relationship for $\mathrm{B}$ given by Equation 14 into the general hyperbolic equation given by Equation 7 gives the load-deflection response for these flexible pavement sections. The correlation between calculated and measured response can be seen in Figure 7.

c. Base Course Deflections

This section analyzes base course deflections $x_{B}$ caused by a rigid bearing plate on the asphaltic concrete surface course layer. The general approach to the analysis is similar to that previously used except that the hyperbolic parameters plotted are

$$
\frac{x_{B} q(d+2 a)}{p d^{2}} \text { versus } \frac{x_{B}}{d+2 a} \text {. }
$$

Essentially, these changes in the parameters reflect the fact that the total force applied to the bearing plate resting on the pavement surface is considered to be uniformly distributed over an area with diameter $d+2 a$ at the top of the base course layer. Of course, the presence of the asphaltic concrete surface course may also contribute a confining effect. Nonetheless, such a technique was found effective in reducing the experimental data to a reasonably compact form.

The above mentioned parameters were plotted for each test analyzed, and coefficients $A$ and $B$ were determined. These coefficients were then investigated to determine their dependence on the various thicknesses of pavement components. The respective equations for the selected plots may be written as

$$
\frac{a b}{d^{2}} A=3(10)^{3.42 D / d-6}
$$

and

$$
\frac{d}{a} B=(10)^{-1.0-3.28 D / d}
$$

Solving Equations 15 and 16 for $A$ and $B$, respectively, and formulating an equation similar to Equation 7 gives an expression describing the general trend of these data.

d. Subgrade Deflections

Subgrade deflections $x_{S}$, which are analyzed in this section, are handled analogous to the base course deflections in the previous section. The total force applied to the bearing plate on the surface is considered uniformly distributed over an area with diameter $d+2 a+2 b$ at the top of the subgrade. The overlying base course and surface course layers may exert a confining effect and hence the response does not necessarily follow the same form as a plate with an assumed uniform pressure resting directly on the subgrade.

The dimensionless hyperbolic parameters

$$
\frac{x_{S} q(d+2 a+2 b)}{p d^{2}} \text { and } \frac{x_{S}}{d+2 a+2 b}
$$


are plotted for each test considered. From these plots the coefficients $A$ and $B$ are determined and examined to deduce their dependence on various pavement component thicknesses. The resulting equations are

$$
\frac{d}{D} A=2.5(10)^{-5.0-2.0 \log D / d}
$$

and

$$
\frac{a b}{d^{2}} B+0.005=3(10)^{2.3 D / d-8}
$$

Equations 17 and 18 may be solved for $A$ and $B$, respectively, and combined with a form of Equation 7 to yield the load-deflection response for the subgrade deflection data.

\section{Temperature Effect}

The pavement deflections in Table 6 of HRB SR 46 are analyzed in this section to determine the effect of temperature on response characteristics. Although less data are involved in this portion, the test procedure, pavement thicknesses, and plate diameters are generally similar. The only essential difference between these data and the data obtained from Table 4 of HRB SR 46 is temperature. Table 6 data were obtained at approximately $45 \pm 5^{\circ} \mathrm{F}$ while Table 4 data were measured around $84 \pm 6^{\circ} \mathrm{F}$.

The hyperibolic coefficients $A$ and $B$ are obtained as functions of $D / d$, and the equations for the approximating curves are

$$
\frac{a b}{d^{2}} A=3(10)^{2.7 D / d^{-6}}
$$

and

$$
B=12(10)^{-2.5 D / d-8}
$$

The results of Equations 19 and 20 may be combined with Equation 7 to yield a general relationship for these data.

The variations in the coefficients of Equations 19 and 20 as compared to Equations 13 and 14 may probably be attributed to the temperature difference between the two sets of tests. For example, taking the ratio between the $A$ values calculated from Equations 13 and 19 will reveal that the initial slope for the load-deflection data corresponding to the lower temperature (Table 6) will be approximately $1.33(10)^{0.63 D / d}$ greater than that for the higher temperature data (Table 4). For $D / d$ equal to 0.3 this ratio of initial slopes would be approximately two.

\section{Effect of Repetitional Loading}

To a limited degree, the effect of repetitional loading can be studied by examining the data recorded in Table 8a of HRB SR 46. The most severe limitation is imposed by the fact that only 75 repetitions are conducted for any given situation. The test procedure employed in obtaining the Table 8a data was a cyclic load and release technique. A pressure of 16 psi is applied to the bearing plate; after the deflection 
measurement is taken, the load is released. In similar fashion pressures of 32,48 , and $64 \mathrm{psi}$ are applied one cycle each. Following the release of the 64 psi pressure, an $80 \mathrm{psi}$ load is applied and released 75 times; deflection measurements were recorded after $1,10,40$, and 75 applications. In general, the data in Table $8 \mathrm{a}$ appear to be more erratic than that in Table 4, and more difficulty was experienced in its analysis.

First of all, the single-cycle data corresponding to applied pressures of $16,32,48$, 64 and $80 \mathrm{psi}$ are analyzed in a manner similar to the preceding approach. The respective equations approximating the coefficients $A$ and $B$ may be written as

$$
\frac{a b}{d^{2}} A=1.6(10)^{5.8 D / d-6}
$$

and

$$
B=0.006-0.037 \frac{D}{d} .
$$

Combining Equations 21 and 22 with Equation 8 produces a general equation describing these data. The differences between the coefficients in Equations 21 and 22 compared to Equations 13 and 14 are most probably attributable to the difference in test procedure between the two sets of data. Using Equations 13 and 21, the ratio of the initial slopes of the load-deflection plot for the Table $8 \mathrm{a}$ data to the Table 4 data may be found to be $2.5(10)^{-2.47 D / d}$; for $D / d$ equal to 0.3 , this ratio becomes approximately one-half. A very pronounced difference is noted between the values for $B$ as obtained from Table 4 and Table 8a data. As can be observed in Figure 6b, Table 4 values for $\mathrm{B}$ tend to become slightly negative as $D / d$ increases; however, a glance at Table 8a values for $B$ will reveal that a large number of these latter tests manifested significantly negative slopes. A negative value for B implies that resistance to deformation is increasing more rapidly than predicted by a linear load-deflection relationship, or the pavement becomes stiffer with increasing load. As can be seen, test procedure does manifest a significant effect on data obtained.

The approach employed in analyzing the effect of repetitional loading was to first determine a dimensionless factor $f$ ratioing the deflection at $N$ applications to the de-

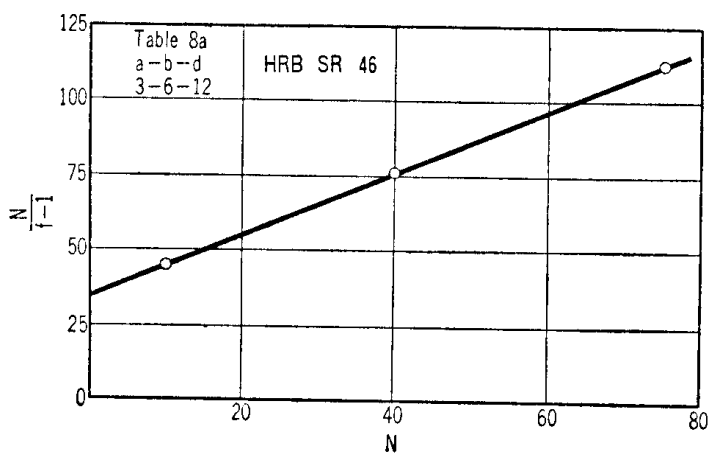

Fig. 8. Typical Plot of Repetitional Deflection Factor versus Number of Load Applications: HRB SR 46 Table 8a Pavement Deflection 
flection at one application for the 80 psi load. This factor was obtained for 10,40 , and 75 load applications. Transformed hyperbolic plots of the dimensionless parameters $N /(f-1)$ and $N$ were made for all cases. In general, these data yielded quite good straight lines; a typical example is shown in Figure 8 . Writing the equation of the straight line as

$$
\frac{N}{f-1}=\alpha+\beta N
$$

the coefficients $\alpha$ and $\beta$ must now be examined to determine their functional dependence on $D / d$. The coefficieent $\alpha$ may be approximated by

$$
\alpha=28 \text {. }
$$

whereas $\beta$ may be described by a straight line whose equation is

$$
\frac{a}{d} \beta=1.44 \frac{D}{d}-0.04 \text {. }
$$

Solving Equation 23 for the factor $f$ and combining with Equations 24 and 25, the effect of repetitional loading for the limited case studied may be expressed as

$$
f=1+\frac{N}{28+\left[1.44 \frac{D}{d}-0.04\right] \frac{d}{a} N},
$$

The factor $f$ is that number by which the single-cycle deflection must be multiplied to obtain the deflection after $\mathrm{N}$ cycles of the same load. Figure 9 gives a correlation plot for calculated and measured values of this factor.

\section{Soil Strength Data}

As previously explained, since neither soil strength data nor moisture content data for the soil directly under a plate test was available, the soil strength for all tests was

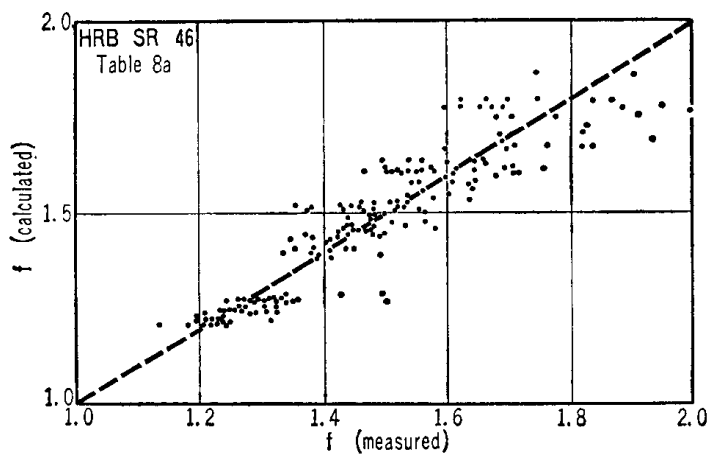

Fig. 9. Correlation Plot of Repetitional Deflection Factor: HRB SR 46 Table 8a Pavement Deflection

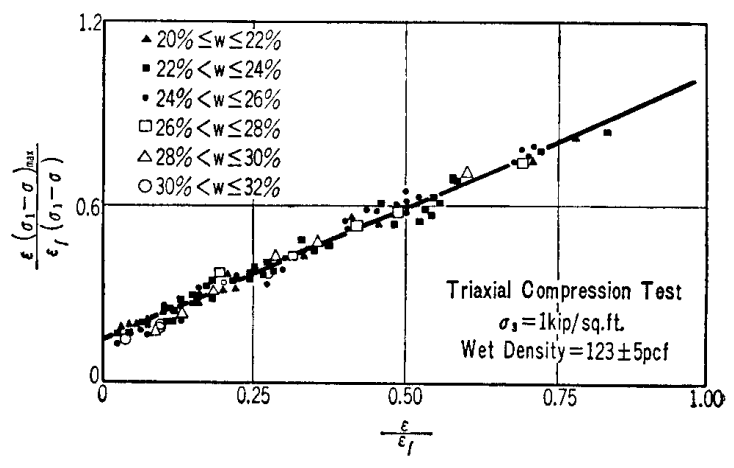

Fig. 10. Transformed Hyperbolic StressStrain Response: Triaxial Test Dat" 
assumed constant and results are given in terms of a normalized soil strength ( $q_{N}$ equals unity). However, data from over thirty triaxial compression tests on the embankment material have been made available by personal correspondence through the courtesy of E. S. Barber. The triaxial tests were conducted with a lateral confining pressure of one kip per square foot; moisture contents ranged from approximately 20 to 32 per cent ; and wet densities varied from approximately 118 to 128 pcf. The stressstrain response is normalized in terms of the maximum deviator stress $\left(\sigma_{1}-\sigma_{3}\right)_{\max }$ and failure strain $\varepsilon_{f}$ in a manner previously described by Krizek and Kondner (19), and results are given in transformed hyperbolic form in Figure 10. For these tests a hyperbolic relation provides a reasonable approximation for constitutive behavior; this equation may be written as

$$
\frac{\left(\sigma_{1}-\sigma_{3}\right)}{\left(\sigma_{1}-\sigma_{3}\right)_{\max }}=\frac{\frac{\varepsilon}{\varepsilon_{f}}}{0.14+0.88 \frac{\varepsilon}{\varepsilon_{f}}}
$$

The consistency indices $\left(\sigma_{1}-\sigma_{3}\right)_{\max }$ and $\varepsilon_{f}$ are shown as functions of moisture content in Figures 11a and 11b. If it were possible to identify the particular test results with a given soil strength, these results could be incorporated into the response equations.

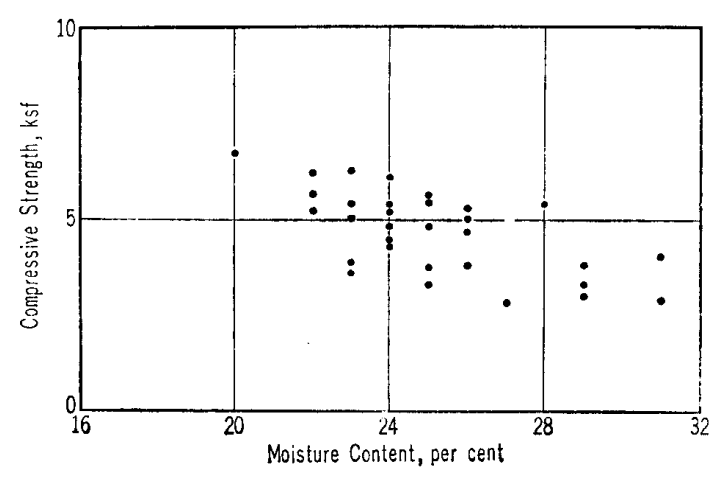

Fig. 11a. Maximum Stress Difference versus Moisture Content

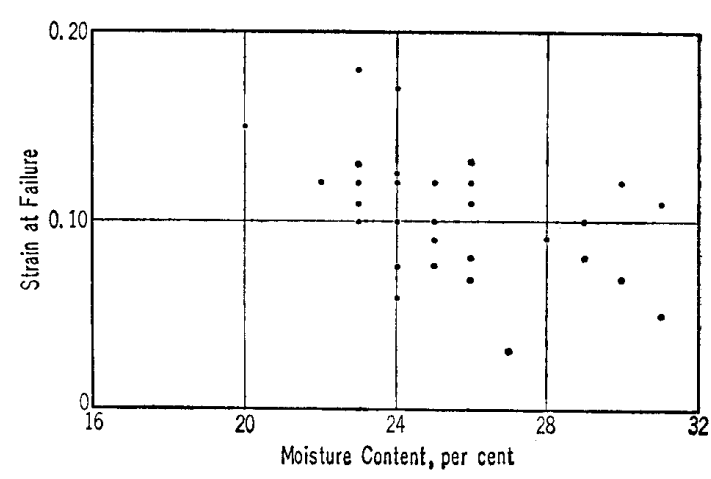

Fig. 11b. Strain at Failure versus Moisture Content

\section{CONCLUSIONS}

Nondimensional techniques have been used to analyze data from rigid plates bearing on flexible pavement sections and various components of these sections. Response equations have been developed to describe pavement load-deflection behavior under a variety of different conditions. The data used were the results of the Hybla Valley Test Program and include effects of different test procedures, temperature, deflections at various layers, and limited repetitive loading (up to 75 repetitions).

It is noted that temperature decrease has an effect of increasing the "stiffness " of the soil-pavement system. Also, the load-deflection response of deflection-controlled and load-controlled tests is found to differ. This indicates that caution must be used 
when attempting any correlation with rigid plate bearing tests. The total deflections from original datum due to repetitive loading increase substantially (up to $80 \%$ or more for 75 load applications) compared to single application deflections. The expression of surface, base course, and subgrade deflections by analytic equations permits an investigation of the effect of layer deflections. Surface deflection alone may be misleading in some cases unless the layer contributing the largest portion of the deflection is known. Although not specifically deduced in this investigation, it appears that rigid plate deflection data would exhibit a response similar to creep speed deflections and correlations between the two could be obtained. Layer deflections take on added significance when it is noted that some studies have indicated no correlation between serviceability parameters and surface deflections. However, others have observed that crack frequency is related statistically to the subbase modulus and deduced that subbase deformations, regardless of scason, contributed to the occurrence of surface cracks. They also concluded that deflection measurements of the individual layers are useful in showing the relationship between pavement cracking and the properties of each layer.

Finally, this study has illustrated a use of dimensional analysis in analyzing experimental data. Indications are that both model and prototype investigations designed and conducted on the basis of nondimensional techqniques might prove effective in reducing unnecessary duplication and contribute toward the development of rational design criteria for flexible pavements.

\section{BIBLIOGRAPHY}

1) Walker, R. D., E. J. Yoder, W. T. Spencer, and R. Lowry, " Significance of Layer Deflection Measurements ", Highway Research Board, Bulletin 321, Washington, D. C., pp. 63-81 (1962).

2) Benkelman, A. C., and S. Williams, "A Co-operative Study of Structural Design of Non-rigid Pavements", Highway Research Board, Special Report No. 46, Washington, D. C. (1959).

Highway Research Board, Washington,'D. C., Vol, 41, pp. 557-590 (1962).

3) Kondner, R. L. and R. J. Krizek, "Correlation of Load Bearing Tests on Soils", Proceedings, Highway Research Board, Washington, D. C., Vol. 41, pp. 557-590 (1962).

4) Kondner, R. L., and R. J. Krizek, “ Non-Dimensional Techniques Applied to Rigid Plate Bearing Tests on Flexible Pavements", Highway Research Board, Bulletin 289, Washington, D. C., pp. 80-90 (1961).

5) Kondner, R. L., " A Non-Dimensional Approach to the Vibratory Cutting, Compaction and Penetration of Soils", Technical Report 8, by the Johns Hopkins University to the U.S. Army, Corps of Engineers, Waterways Experiment Station, Vicksburg, Mississippi (1960).

6) Yoder, E. J., "Flexible Pavement Deflections-Methods of Analysis and Interpretation", Proceedings, Association of Asphalt Paving Technologists, Vol. 31, pp. 260-288 (1962).

7) Burmister, D. M., "The Theory of Stresses and Displacements in Layered Systems and Application to the Design of Airport Runways", Proceedings, Highway Research Board, Washington, D. C. (1943).

8) Burmister, D.M., "Stress and Displacement Characteristics of a Two Layer Rigid Base Soil System : Influence Diagrams and Practical Applications ", Proceedings, Highway Research Board, pp. 773-814 (1956).

9) Fox, L., " Computation of Traffic Stresses in a Simple Road Structure ", Road Research, Technical Paper No. 9, Road Research Laboratory, London, England (1948). 
10) Jones, A., “ Tables of Stresses in Three-Layer Elastic Systems ", Highway Research Board, Bulletin 342, Washington, D. C., pp. 176-214 (1962).

11) Palmer, L. A., and E. S. Barber, "Soil Displacement Under a Circular Loaded Area ", Proceedings, Highway Research Board, Washington, D. C. (1940).

12) Baker, R. F., and H. S. Papazian, "The Effect of Stiffness Ratio on Pavement Stress Analysis", Proceedings, Highway Research Board, Washintong, D. C. (1960).

13) Ingimarsson, G. R., "An Analysis of Hybla Valley Rigid Plate Bearing Data ", Highway Research Board, Bulletin 299, Washington, D. C., pp. 22-41 (1961).

14) Housel, W. S., " A Practical Method for the Selection of Foundations Based on Fundamental Research in Soil Mechanics ", Engineering Research, Bulletin No. 13, University of Michigan (1929).

15) Housel, W. S., "Discussion-An Analysis of Hybla Valley Rigid Plate Bearing Data", Highway Research Board, Bulletin 289, Washington, D. C., pp. 41-43 (1961).

16) Kondner, R. L., and R. J. Krizek, "A Non-Dimensional Approach to the Static and Vibratory Loading of Footings ", Highway Research Board, Bulletin 277, Washington, D. C., pp. 37-60 (1960).

17) Kondner, R. L., "Hyperbolic Stress-Strain Response: Cohesive Soils", Proceedings, ASCE, Journal of the Soil Mechanics and Foundation Division, Vol. 89, No. SM1, pp. 115-143 (1963).

18) The AASHO Road Test, Report 5, Pavement Research, Highway Research Board, Special Report No. 61E, Washington, D. C. (1962).

19) Krizek, R. J., and R. L. Kondner, "Strength-Consistency Indices for a Cohesive Soil", Highway Research Board, Record Number 48, pp. 1-18, (1964).

(Received: June 23, 1966) 